\title{
EL ORDEN PÚBLICO PROCESAL Y EL DERECHO DE DEFENSA EN EL EXEQUÁTUR DEL LAUDO ARBITRAL
}

\section{PUBLIC PROCEDURAL POLICY AND THE RIGHT OF DEFENCE IN THE EXEQUATUR OF THE ARBITRAL AWARD}

\author{
Carmen María Noriega Linares \\ Doctoranda en Derecho por la Universidad de Murcia \\ Letrada colegiada ejerciente del Ilustre Colegio de Abogados de Murcia
}

Recibido: 15.06.2021 / Aceptado: 08.07.2021

DOI: https://doi.org/10.20318/cdt.2021.6299

\begin{abstract}
Resumen: la situación de ausencia del demandado en un procedimiento puede deberse por múltiples causas y también producir varias consecuencias. En el auto del TSJ de Madrid la ausencia se produce en el procedimiento de exequátur, por lo que las consecuencias que de ello se derivan serán diferentes de las que se habrían producido de haber estado ausente durante el procedimiento ante el tribunal extranjero.

La excepción del orden público internacional en su vertiente procesal en conjunción con el derecho de defensa juega un papel esencial para otorgar o denegar el exequátur, pues el poder defenderse en juicio es un principio fundamental que está protegido, tanto a nivel nacional como internacional. Sin embargo, no toda limitación de este derecho es una violación automática del orden público internacional.

Palabras clave: orden público procesal, derecho de defensa, art. 24 Constitución Española, procedimiento de exequátur, denegación reconocimiento, laudo arbitral, resolución judicial, Ley de Cooperación Jurídica Internacional, Ley de Enjuiciamiento Civil.
\end{abstract}

Abstract: the situation of absence of the defendant in a proceeding can be due to multiple causes and also produce several consequences. In the order of the TSJ of Madrid, the absence occurs in the exequatur procedure, so the consequences of this will be different from those which would have occurred if the defendant had been absent during the proceedings before the foreign court.

The exception of the international public policy in its procedural aspect in conjunction with the right of defence plays an essential role in granting or refusing the exequatur, because being able to defend oneself in court is a fundamental principle that is protected, both nationally and internationally. However, not every limitation of this right is an automatic violation of international public policy.

Keywords: Procedural public policy, right of defence, art. 24 Spanish Constitution, exequatur procedure, refusal of recognition, arbitral award, judicial decision, International Legal Cooperation Act, Civil Procedure Act.

Sumario: I. Antecedentes de hecho. II. Regulación de la denegación del reconocimiento del laudo. 1. La vulneración del derecho de defensa. A) En el procedimiento de arbitraje. B) En el procedimiento de exequátur. 2. La vulneración del orden público internacional en su vertiente procesal y el derecho de defensa. A) El derecho de defensa en Europa. B) El derecho de defensa en Derecho español. III. Conclusiones. 


\section{Antecedentes de hecho}

1. Las mercantiles "SIDDIQSONS TINPLATE, LTD", de origen pakistaní, y "THE CENTURION TETRA, SL", con nacionalidad española, acuden a la Corte de Arbitraje de la Cámara de Comercio Internacional sita en París para resolver por vía arbitral el litigio surgido entre ambas. El 13 de junio de 2019 emite la Corte un laudo en el que se acuerda que hubo un incumplimiento de un contrato por parte de la mercantil española, pero que también lo hubo de otro por parte de la pakistaní. Como consecuencia de ambos incumplimientos se impusieron unas medidas para reestablecer o compensar las partes realizadas o sancionar por lo no realizado.

2. Se presenta por Siddiqsons ante el Tribunal Superior de Justicia de Madrid la demanda de reconocimiento de laudo o resolución arbitral extranjera, en la cual alegaba los hechos y fundamentos que estimó oportunos, y solicitó que se homologase el laudo a fin de reconocer la eficacia en España, para solicitar cuando procediese el despacho de ejecución.

3. Registrada la demanda se le da traslado a la demandada para que en el plazo de treinta días se personara y formulase escrito de contestación. Igualmente se le da traslado al Ministerio Fiscal, el cual evacuó un informe en el que, en base a las alegaciones que estimó oportunas, señaló la procedencia del reconocimiento del laudo a efectos de su validez en España por el correspondiente Juzgado Civil de Madrid que por turno de reparto correspondiese. Por su parte la demandada no presentó contestación ni se opuso.

4. Se señala para la deliberación y resolución el 27 de Octubre de 2020, el 9 de Noviembre de 2020 se dicta un auto por el que se concedía el reconocimiento.

\section{Regulación de la denegación del reconocimiento del laudo}

5. En lo que respecta al supuesto que ocupa el presente comentario, se va a partir del hecho de que se dicta sentencia estimatoria del reconocimiento en España con ausencia del demandado en el proceso. Forma parte fundamental del sistema jurídico español el derecho de audiencia del demandado, según el cual todas las personas tienen derecho a obtener la tutela efectiva de los jueces sin que se produzca indefensión, es lo que tradicionalmente se conoce como ser oído y vencido en juicio. Este principio se encuentra consagrado en el art. 24 de la Constitución Española (CE en adelante) y se incluye dentro del entramado del orden público internacional procesal del que se hablará más adelante, por constituir el derecho de defensa de cualquier sujeto.

6. Antes de examinar con mayor atención esta cuestión, hay que tener claro cuáles son las normas que van a regular este tema. Por ello, en primer lugar hay que acudir a las normas internacionales a las que España se ha adherido, por lo que forman parte de su ordenamiento jurídico, donde aparece el Convenio sobre Reconocimiento y Ejecución de Sentencias Arbitrales Extranjeras, realizado en Nueva York en 1958 (CNY en adelante) $)^{1}$ y el Convenio Europeo sobre Arbitraje Comercial Internacional, hecho en Ginebra en 1961 (CG en adelante $)^{2}$.

7. Sobre el reconocimiento el CG guarda silencio absoluto, pero no así el CNY. En él el art. V regula las causas de denegación del reconocimiento o ejecución del laudo arbitral, que se dividen en dos: el primer apartado son las causas oponibles por las partes; y el segundo, las causas apreciables de oficio, entre las que se encuentra la excepción de orden público internacional. Entre las causas que se pueden invocar por las partes está el hecho de no haber podido hacer valer los medios de defensa. En concreto, el art. V.1.b) establece como causa de denegación del reconocimiento el que la parte contra la

\footnotetext{
1 Traspuesto en España en el BOE núm. 164, de 11 de julio de 1977, págs. 15511 a 15512. (Ref. BOE-A-1977-15727).

2 Traspuesto en España en el BOE núm. 238, de 4 de octubre de 1975, págs. 20985 a 20988. (Ref. BOE-A-1975-20601).
} 
que se invoca la sentencia arbitral no ha podido hacer valer sus medios de defensa por cualquier razón en el procedimiento arbitral. Es decir, se produjo alguna circunstancia en el proceso arbitral por el que se vio impedido de realizar las actividades necesarias para su defensa.

8. Dentro de la legislación emanada de los poderes nacionales, es la Ley 60/2003 de Arbitraje

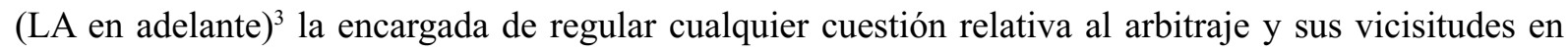
España. El Título IX, formado únicamente por el art. 46, es el encargado de regular el exequátur de los laudos extranjeros. El apartado primero define qué se entiende por laudo extranjero y el segundo qué norma regirá el exequátur de los laudos extranjeros, y lo hace mediante la remisión al CNY. No obstante lo anterior, añade que el procedimiento para el reconocimiento se sustanciará mediante las normas procesales civiles existentes para el reconocimiento de sentencias dictadas por tribunales extranjeros. Por tanto, encontramos aquí una remisión a las normas civiles generales y especiales en la materia de reconocimiento de sentencias extranjeras para determinar qué procedimiento será el que habrá de seguirse.

9. Mediante esa remisión la Ley de Enjuiciamiento Civil (LEC en adelante) ${ }^{4}$ adquiere la competencia para establecer el procedimiento a seguir en este caso. El art. 523 versa sobre la ley aplicable al procedimiento. En especial, el apartado primero indica que "Para que las sentencias firmes y demás títulos ejecutivos extranjeros lleven aparejada ejecución en España se estará a lo dispuesto en los Tratados internacionales y a las disposiciones legales sobre cooperación jurídica internacional". Añade el apartado segundo que en cualquier caso la ejecución se llevará a cabo conforme a las disposiciones de la LEC, salvo que los Tratados internacionales vigentes en España dispusieren otra cosa.

10. A modo de resumen, son varias las leyes que tratan el arbitraje, el reconocimiento de laudos arbitrales extranjeros y el procedimiento a seguir, todas coinciden en el hecho de que el orden público internacional prima y debe ser protegido en aquellos casos en los que el reconocimiento de un laudo extranjero vulnera un principio fundamental del Derecho del país receptor, en el supuesto tratado, se trataría del Derecho español. Hay que recalcar que se trata de una cláusula excepcional para casos extraordinarios en los que se produce tal vulneración, por lo que su aplicación no es aleatoria sino que responde a la observancia de unas causas concretas. Además, completa el CNY en el art. V.1.b) que la vulneración de los derechos de defensa también son causa de denegación del reconocimiento, aunque esa vulneración debe haberse producido en el procedimiento arbitral, por lo que guarda silencio sobre qué ocurriría si la rebeldía se produce en el proceso de homologación en el que se solicita el reconocimiento o la ejecución del laudo extranjero.

\section{La vulneración del derecho de defensa}

\section{A) En el procedimiento de arbitraje}

11. El art. V.1.b) CNY señala que se podrá denegar el reconocimiento o exequátur cuando “(...) la parte contra la cual se invoca la sentencia arbitral no ha sido debidamente notificada de la designación del árbitro o del procedimiento de arbitraje o no ha podido, por cualquier otra razón, hacer valer sus medios de defensa". Por ello se hace necesario dar un paso atrás y estudiar qué ha sucedido en el procedimiento arbitral y si se ha dictado o no en ausencia del demandado. Más adelante se hablará del derecho de defensa con más profundidad, por lo que basta decir aquí que éste es un derecho fundamental reconocido a nivel internacional en el Convenio Europeo de Derechos Humanos. Además, debe apreciarse en todo procedimiento, ya sea judicial o extrajudicial, con la particularidad de que su extensión puede limitarse, pero siempre de forma justificada.

\footnotetext{
${ }^{3}$ Ley 60/2003, de 23 de diciembre, de Arbitraje. (BOE núm. 309, de 26 de diciembre de 2003. Ref. BOE-A-2003-23646)

${ }^{4}$ Ley 1/2000, de 7 de Enero, de Enjuiciamiento Civil (BOE núm. 7, de 8 de enero de 2000. Ref. BOE-A-2000-323).
} 
12. Sin embargo, aunque se puede limitar, debe dársele la oportunidad al demandado para que haga uso de este derecho. Para ello, primero se debe notificar a la parte sobre la existencia de un procedimiento. Es por ello que el no haber sido notificado, o no haberlo sido debidamente, es considerado una vulneración del derecho de defensa, pues si no se tiene conocimiento de la existencia de algo en su contra, difícilmente podrá la parte personarse y actuar. A pesar de la importancia que reviste el hecho de la notificación, el CNY no establece la forma en que debería hacerse o cuáles serían los mínimos necesarios que deben aparecer para considerar que se ha intentado realizar esa notificación.

13. Puesto que nada dice el CNY sobre la notificación, habría que acudir a la Ley aplicable elegida por las partes o, en su defecto, a la ley de la sede del tribunal arbitral, la cual sería la aplicable en ausencia de acuerdo por las partes ${ }^{5}$. Como nada se dice en el auto sobre qué ley fue la elegida por las partes para regular el procedimiento arbitral, se va a suponer que la elegida fue la de la sede arbitral.

14. La Corte de Arbitraje de la Cámara de Comercio Internacional cuenta con un reglamento ${ }^{6}$, por lo que se va a suponer que, puesto que fue la sede de arbitraje, también fueron las reglas a las que se sometió el procedimiento de arbitraje. En este reglamento se dispone, entre otras cuestiones, el régimen de notificaciones a seguir. Más específicamente, el artículo $3^{7}$ apartado 2 señala que todas las notificaciones se harán a la última dirección conocida de la parte o de su representante. Además, prosigue el precepto con la enumeración de los medios válidos para realizar la notificación, tales como entrega contra recibo, correo certificado, mensajería correo electrónico o cualquier otro medio de telecomunicación que deje constancia de su envío. En cualquier caso, debe quedar constancia de haberse realizado dicha notificación.

15. Para poder decidir si la notificación se hizo o no conforme a Derecho, el tribunal que conozca del exequátur deberá hacer un doble examen. Por un lado, el juzgador debe analizar las normas procesales del Estado donde se localice la sede arbitral, relativas a la forma de las notificaciones; y, por otro lado, deberá estudiar cómo se ha realizado la notificación en función de las normas del Estado de destino. ${ }^{8}$ Una vez realizado el control de la forma de la notificación, es necesario comprobar que además se hizo de manera que el demandado tuvo tiempo suficiente para defenderse. Y es que no basta con que se haya evidenciado que la notificación fue correcta, todavía podrá negarse el reconocimiento de esa resolución si el demandado no dispuso de tiempo suficiente para defenderse. "Esta segunda condición tiene un carácter fáctico, pues el juez requerido deberá apreciar si atendiendo a las circunstancias con-

${ }^{5}$ En este sentido el art. V.1.d) CNY establece como causa de denegación del reconocimiento o exequátur del laudo arbitral extranjero el "Que la constitución del Tribunal arbitral o el procedimiento arbitral no se han ajustado al acuerdo celebrado entre las partes o, en defecto de tal acuerdo, que la constitución del Tribunal arbitral o el procedimiento arbitral no se han ajustado a la Ley del país donde se ha efectuado el arbitraje". Mediante esta dicción el precepto pone de manifiesto que en ausencia de Ley elegida por las partes, posibilidad otorgada gracias a la autonomía de la voluntad que rige el procedimiento arbitral, se estará a lo dispuesto en la ley del país donde se ha realizado el arbitraje, también llamada ley de la sede arbitral.

${ }^{6}$ https://www.iccspain.org/wp-content/uploads/2021/01/ICC-2021-Arbitration-Rules-english-version.pdf

7 Article 3: Written Notifications or Communications; Time Limits: “1) Save as otherwise provided in Articles 4(4)(b) and 5(3), all pleadings and other written communications submitted by any party, as well as all documents annexed thereto, shall be sent to each party, each arbitrator, and the Secretariat. Any notification or communication from the arbitral tribunal to the parties shall also be sent in copy to the Secretariat. 2) All notifications or communications from the Secretariat and the arbitral tribunal shall be made to the last address of the party or its representative for whom the same are intended, as notified either by the party in question or by any other party. Such notification or communication may be made by delivery against receipt, registered post, courier, email, or any other means of telecommunication that provides a record of the sending thereof. 3) A notification or communication shall be deemed to have been made on the day it was received by the party itself or by its representative, or would have been received if made in accordance with Article 3(2). 4) Periods of time specified in or fixed under the Rules shall start to run on the day following the date a notification or communication is deemed to have been made in accordance with Article 3(3). When the day next following such date is an official holiday, or a non-business day in the country where the notification or communication is deemed to have been made, the period of time shall commence on the first following business day. Official holidays and non-business days are included in the calculation of the period of time. If the last day of the relevant period of time granted is an official holiday or a nonbusiness day in the country where the notification or communication is deemed to have been made, the period of time shall expire at the end of the first following business day."

${ }^{8}$ N. Marchal Escalona. Garantías procesales y notificación internacional, Comares, Granada, 2001, pp. 327 y 328 y ss. 
cretas del caso el demandado tuvo tiempo suficiente para preparar su defensa y llevarla a cabo ; con tal objeto incluso podría tomar en consideración circunstancias posteriores a la notificación ${ }^{10}$. De esta manera, una resolución en el Estado de origen sobre el primero de los requisitos -notificación regularno dispensa al Juez requerido de la obligación de proceder al examen del segundo requisito, incluso si dicha resolución fue dictada en un procedimiento contradictorio distinto ${ }^{11},{ }^{12}$

16. Sin embargo, es posible que esta ausencia se deba a otros motivos inherentes al comportamiento de una de las partes y no a una deficiencia en la notificación. En estos supuestos es el art. 25 de la Ley Modelo de la Comisión de las Naciones Unidas para el Derecho Mercantil Internacional sobre Arbitraje Comercial Internacional ${ }^{13}$ el encargado de resolver la cuestión de qué ocurriría en este caso. Como dice el precepto, si la rebeldía es del actor que inicia el arbitraje, el procedimiento se dará por concluido. Por el contrario, si esa rebeldía es de la contraparte, “(...) el tribunal arbitral continuará las actuaciones, sin que esa omisión se considere por sí misma como una aceptación de las alegaciones del demandante”. Así pues, se continuarán las actuaciones incluso en ausencia del demandado.

17. Esto presenta diversas cuestiones, "(p)or un lado, esta disposición faculta al tribunal arbitral para continuar con el procedimiento a pesar de la rebeldia del demandado, pero por otra parte, prohibe a los árbitros dictar un laudo favorable al reclamante automáticamente. En otras palabras, el tribunal arbitral no tiene permitido elaborar conclusiones negativas debido a la inactividad del demandado." ${ }^{14}$. Se abren así serias dificultades para el árbitro, que deberá resolver la cuestión sin parcialidades, aunque sólo obtenga información unilateral.

\section{B) En el procedimiento de exequátur}

18. Todo lo anterior es aplicable cuando la rebeldía se produce en el procedimiento de origen, pero cuestión distinta es qué ocurre cuando la ausencia del demandado aparece en el procedimiento de reconocimiento. Tal y como se ha dicho, el régimen de denegación de reconocimiento previsto en el CNY es de aplicación cuando la resolución que se pretende reconocer se dictó con ausencia del demandado pero sólo cuando esta ausencia fueron por causas no imputables a la parte, pues de ser una rebeldía voluntaria el procedimiento continuaría su cauce normal. Para saber qué sucede cuando esa ausencia se produce en el procedimiento de reconocimiento o exequátur habrá que acudir a otras leyes.

19. Al hablar sobre la regulación aplicable a la denegación del reconocimiento, se ha puesto de manifiesto que el CNY no contiene ninguna norma sobre el procedimiento a seguir y que la LA se remite a las leyes procesales civiles. Esa remisión lleva hasta la LEC, donde el art. 523 LEC es el encargado de regular la ley aplicable al procedimiento de los títulos ejecutivos en España. El primer apartado se remite a lo contenido en tratados internacionales y disposiciones legales sobre cooperación jurídica internacional, y el apartado segundo indica que en todo caso se aplicarán las disposiciones contenidas en ella para la ejecución de sentencias y títulos ejecutivos extranjeros y, por remisión de la LA, también de los laudos extranjeros.

\footnotetext{
9 STJCE de 16 de junio de 1981, asunto C-166/80, Klomps c. Michel (Rec. 1981 -01593)

${ }_{10}$ STJCE de 11 de junio de 1985, asunto C-49/84, Leon Emile Gaston Carlos Debaecker and Berthe Plouvier v Cornelis Gerrit Bouwman (Rec. 1985 -01779)

${ }^{11}$ STJCE de 16 de junio de 1981, asunto C-166/80, Klomps c. Michel (Rec. 1981 -01593)

12 C.I. Cordero Álvarez. "La rebeldía del demandado en el control de las garantías procesales como causa de denegación del reconocimiento en la Ley de Cooperación Jurídica Internacional: una visión comparada con el sistema de Bruselas". Revista electrónica de estudios internacionales. 2016. Págs. 1-38. DOI: 10.17103/reei.32.02

${ }^{13} \mathrm{https}$ //uncitral.un.org/sites/uncitral.un.org/files/media-documents/uncitral/es/ml-arb-s.pdf

${ }^{14}$ N. Sievi. "Enfrentando al demandado en rebeldía: un reto para los árbitros y el reclamante". Traducción de D. S. AgUIRRE Rosas. Revista Latinoamericana de Derecho Comercial Internacional. No 1. Vol. 3. Año 2015. Págs. 254-271. ISSN: 2007-7440.
} 
20. La norma de cooperación jurídica en España es la Ley de Cooperación Jurídica Internacional (LCJI en adelante $)^{15}$. Antes de continuar, hay que explicar que si bien el reconocimiento y el exequátur son figuras jurídicas distintas con consecuencias diferentes, la LCJI engloba ambos términos bajo el nombre de "procedimiento de exequátur". Lo que la parte actora insta es el reconocimiento del laudo arbitral, pero en el auto lo que se concede es el exequátur. En este sentido el art. 42 expone que el "procedimiento para declarar a título principal el reconocimiento de una resolución judicial extranjera y, en su caso, para autorizar su ejecución se denominará procedimiento de exequátur”. Por ello, aunque el título de este apartado se titula "procedimiento de exequátur", en realidad se habla del reconocimiento, que fue lo que instó la actora.

21. M. Gómez Jene ${ }^{16}$, en su comentario al anteproyecto de la LCJI, pone de manifiesto que el nuevo procedimiento de exequátur que instauró el legislador en la LCJI, y que sustituye al contenido en la LEC 1881, es de aplicación únicamente a las resoluciones judiciales. Por ello, continua el autor, no se tuvo en cuenta que también se aplicará al exequátur del laudo arbitral extranjero y, como consecuencia, los artículos relacionados con este procedimiento deberán reinterpretarse para su correcta aplicación al reconocimiento del laudo.

22. El artículo encargado de regular el procedimiento de reconocimiento es el 54 . En él se contienen las reglas necesarias para determinar los pasos a seguir para poder reconocer la sentencia arbitral. El apartado 4 añade los documentos que se tendrían que acompañar junto con la demanda de solicitud de ejecución, en especial el subapartado b) señala que se debe acompañar del “(...) documento que acredite, si la resolución se dictó en rebeldía, la entrega o notificación de la cédula de emplazamiento o el documento equivalente". Se pone de manifiesto la importancia ya señalada con anterioridad, de que esa rebeldía fuese por una notificación deficiente y no por la voluntad del demandado.

23. El art. $496 \mathrm{LEC}^{17}$ trata la declaración de rebeldía y establece que ésta no se considerará en ningún caso allanamiento o admisión tácita de los hechos. En este sentido, "conviene recordar que la falta de contestación en tiempo a la demanda o la declaración de rebeldía no equivalen en ningún caso al allanamiento ni suponen reconocimiento de hechos, ni confesión, ni acarrean una "poena probati" para el demandado, teniendo que probar el actor igualmente los fundamentos de sus alegaciones, en definitiva, pues, la extemporaneidad o la falta de la contestación únicamente producen un efecto preclusivo respecto a la misma y sólo suponen la pérdida de esa posibilidad procesal, lo que no impide que el demandado comparezca en cualquier momento pudiendo proponer prueba, intervenir en la de la actora, recurrir etc, en definitiva, realizar cualquier actuación procesal en su defensa siempre que no haya precluido el momento procesal para hacerlo. Tal preclusión produce dos consecuencias: a) precluye la posibilidad de oponer excepciones, no sólo las procesales, sino también aquellas otras configuradoras de hechos extintivos, impeditivos, excluyentes o modificativos de la pretensión del actor (que, no obstante, mantiene la carga de la prueba de los hechos constitutivos de la misma) y b) tampoco podría proponer otras pruebas que aquellas que pudieran afectar a los "hechos" de la demanda."18

24. Se pueden extraer de todo lo anterior a modo de resumen dos ideas. La primera y principal es que la rebeldía no se puede considerar allanamiento o aceptación de los hechos; la segunda es la consecuencia que va a tener la ausencia del demandado en el proceso. De un lado, la preclusión de los plazos procesales para ejercitar sus derechos de defensa y, por otro lado y como consecuencia de la precedente,

${ }^{15}$ Ley 29/2015, de 30 de julio, de Cooperación Jurídica Internacional en Materia Civil (BOE núm. 182, de 31 de julio de 2015. Ref. BOE-A-2015-8564).

${ }^{16}$ M. Gómez Jene. “Arbitraje internacional y Anteproyecto de Ley de Cooperación Jurídica Internacional en Materia Civil”. Diario La Ley. ISSN 1989-6913, nº 8388, 30 de septiembre 2014. Págs. 2-7.

17 Art. 496 LEC: "1. El Letrado de la Administración de Justicia declarará en rebeldía al demandado que no comparezca en forma en la fecha o en el plazo señalado en la citación o emplazamiento, excepto en los supuestos previstos en esta ley en que la declaración de rebeldía corresponda al Tribunal. 2. La declaración de rebeldía no será considerada como allanamiento ni como admisión de los hechos de la demanda, salvo los casos en que la ley expresamente disponga lo contrario".

18 SAP Barcelona 202/2021, de 31 de marzo de 2021. ECLI:ES:APB:2021:3270 
la pérdida de oportunidad de que el juez valore y pueda llegar a desestimar la demanda presentada contra él, en este caso sería la demanda de exequátur.

25. Una vez explicada las distintas consecuencias que tiene la ausencia del demandado en el procedimiento arbitral y en el de reconocimiento se puede volver al auto objeto de este estudio. En los antecedentes nada se dice si el laudo se dictó con ausencia o no de la parte demandada, pero sí en el procedimiento de reconocimiento. Tal y como se ha expuesto, el hecho de que la ausencia se produjese en el proceso para solicitar el reconocimiento, no supone nada más allá que la preclusión de los plazos para poder ejercitar su derecho de defensa. Por ende, el tribunal que resolvió el reconocimiento lo hizo correctamente.

\section{La vulneración del orden público internacional en su vertiente procesal y el derecho de defensa}

26. El orden público internacional es una excepción cuya aparición constituye elemento clave para aceptar o denegar el reconocimiento y ejecución de una resolución extranjera, en este caso, del laudo arbitral extranjero. Es un concepto jurídico indeterminado, dotado de contenido por los propios países en base a su moral, principios generales y normas imperativas nacionales, por lo que los conceptos que incluye podrán variar de un Estado a otro ${ }^{19}$. Aunque su nombre contenga la nomenclatura de "internacional" en realidad es de corte nacional ${ }^{20}$, pues cada Estado cuenta con sus propios principios y normas imperativas, las cuales constituyen el objeto de protección de esta excepción. Por tanto, cada país tiene su propio orden público internacional y deviene "internacional" porque se activa cuando se introduce una ley extranjera en el país cuyos tribunales conocen del asunto, los cuales deben garantizar la cohesión jurídica de su sociedad. Además, esta noción se divide a su vez en otros dos que son el orden público internacional material y el orden público internacional procesal.

27. La sentencia del Tribunal Constitucional 46/2020, de 15 de junio ${ }^{21}$ define ambas vertientes en base a reiterada jurisprudencia. Por un lado, el orden público internacional material está integrado por "el conjunto de principios jurídicos públicos, privados, políticos, morales y económicos, que son absolutamente obligatorios para la conservación de la sociedad en un pueblo y en una época determinada (SSTC 1571987, de 11 febrero; 116/1988, de 20 junio, y 54/1989, de 23 febrero)'”. Por su parte, define el orden público internacional procesal como "el conjunto de formalidades y principios necesarios de nuestro ordenamiento jurídico procesal". Si bien es cierto que ambas definiciones constituyen un concepto bastante amplio que abarca un gran número de supuestos, también lo es que no se trata de una excepción de fácil aplicación y justificación. Todo ello en aras al fomento de la libre circulación de resoluciones extranjeras por el espacio europeo.

\section{A) El derecho de defensa en Europa}

28. El artículo 6 del Convenio Europeo de Derechos Humanos (CEDH en adelante) ${ }^{22}$ protege el derecho de todo ciudadano a un proceso equitativo. El precepto se divide en 3 subapartados, donde el

19 L.A. López Zamora. "Comentarios Sobre el Orden Público Internacional en sede arbitral internacional, su funcionalidad y su interrelación con el Derecho Internacional Público”. Cuadernos de Derecho Transnacional. Octubre 2018. Vol 10, nº 2. Pág. 526.

${ }^{20}$ A.-L- Calvo Caravaca/ J. Carrascosa González. "Derecho Internacional Privado. Volumen I". Decimoquinta Edición. Ed. Comares. 2014.

${ }^{21}$ STC 46/2020, de 15 de junio. ECLI:ES:TC:2020:46

22 Art 6 CEDH: "Derecho a un proceso equitativo 1. Toda persona tiene derecho a que su causa sea oída equitativa, públicamente y dentro de un plazo razonable, por un Tribunal independiente e imparcial, establecido por ley, que decidirá los litigios sobre sus derechos y obligaciones de carácter civil o sobre el fundamento de cualquier acusación en materia penal dirigida contra ella. La sentencia debe ser pronunciada públicamente, pero el acceso a la sala de audiencia puede ser prohibido a la prensa y al público durante la totalidad o parte del proceso en interés de la moralidad, del orden público o de la seguridad nacional en una sociedad democrática, cuando los intereses de los menores o la protección de la vida privada de las partes 
primero indica que todo ciudadano tiene derecho a que su causa sea oída equitativa y públicamente dentro de un plazo razonable y, el tercero, que tiene derecho a que se le informe de la acusación formulada contra él dentro de un plazo razonable para poder preparar su defensa y poder defenderse a sí mismo o por medio de representante, entre otros derechos

29. Queda patente la importancia que tiene el derecho de defensa para la Unión Europea (UE en adelante), pues comporta uno de los Derechos Fundamentales que protege. Éstos forman parte de los principios generales del Derecho, cuyo respeto lo garantiza el Tribunal de Justicia de la UE (TJUE en adelante $)^{23}$. Están inspirados tanto en las tradiciones constitucionales comunes a todos los Estados, así como por las indicaciones proporcionadas por los instrumentos internacionales relativos a la protección de los Derechos Humanos, en los cuales han cooperado los Estados en su formulación o se han adherido, como es el CEDH.

30. No hay que confundirse y pensar que el orden público internacional forma parte de estos principios generales. Es más bien al contrario, pues los principios generales forman parte del orden público internacional. Como si de una montaña se tratase, las piedras que están en la base son los principios generales del Derecho y las normas imperativas de un Estado y, conforme se va subiendo en la montaña, hay conceptos más específicos y concretos de ese Estado. Y es que el contenido que tiene orden público internacional es creado por cada Estado, son conceptos nacionales ${ }^{24}$ aplicados a situaciones internacionales, por lo que lo comprendido dentro del orden público internacional puede ser distinto en función del país que lo aplique. Sin embargo, y aunque sean los Estados quienes decidan qué incluir dentro de este concepto, será el TJUE el encargado de determinar los límites dentro de los cuales los tribunales nacionales van a poder denegar el reconocimiento de una resolución dictada por un órgano jurisdiccional de otro Estado ${ }^{25}$, pues no hay que olvidar que se trata de una excepción, y por ende no puede aplicarse indiscriminadamente. Pero la intervención del TJUE también está condicionada, ya que depende de si se aplica normativa europea o no.

31. Puesto que es el TJUE el encargado de establecer los límites de actuación del orden público internacional, el resto del epígrafe se desarrollará siguiendo lo dicho por él, esencialmente en la STJUE Krombach, referente por antonomasia del tema tratado. En ella el TJUE indica que los tribunales no podrán hacer uso de la excepción del orden público internacional de manera discrecional para denegar el reconocimiento o ejecución de cualquier resolución extranjera, por el mero hecho de existir una divergencia de norma jurídica entre la que aplicó el tribunal de origen y la que habría aplicado el tribunal al que se le pide el reconocimiento. No hay que olvidar que el procedimiento de exequátur no es otra instancia ${ }^{26}$, por lo que el tribunal encargado de conceder o denegar el exequátur no podrá entrar a conocer sobre el fondo del asunto o hacer valoraciones del contenido o motivación, únicamente podrá decir si esa resolución, o laudo, es o no contraria al orden público internacional del país y, por tanto, si lo reconoce o no. ${ }^{27}$

en el proceso asi lo exijan 1011 o en la medida en que sea considerado estrictamente necesario por el tribunal, cuando en circunstancias especiales la publicidad pudiera ser perjudicial para los intereses de la justicia. 2. Toda persona acusada de una infracción se presume inocente hasta que su culpabilidad haya sido legalmente declarada. 3. Todo acusado tiene, como mínimo, los siguientes derechos: a) a ser informado, en el más breve plazo, en una lengua que comprenda y de manera detallada, de la naturaleza y de la causa de la acusación formulada contra él; b) a disponer del tiempo y de las facilidades necesarias para la preparación de su defensa; c) a defenderse por sí mismo o a ser asistido por un defensor de su elección y, si carece de medios para pagarlo, a poder ser asistido gratuitamente por un abogado de oficio, cuando los intereses de la justicia asi lo exijan; d) a interrogar o hacer interrogar a los testigos que declaren en su contra y a obtener la citación e interrogatorio de los testigos que declaren en su favor en las mismas condiciones que los testigos que lo hagan en su contra; e) a ser asistido gratuitamente de un intérprete si no comprende o no habla la lengua empleada en la audiencia."

${ }^{23}$ STJUE de 28 de marzo de 2000, asunto C-7/98, Krombach, ECLI:EU:C:2000:164

${ }^{24}$ A.-L- Calvo Caravaca/ J. Carrascosa González. "Derecho Internacional Privado. Volumen I". Decimoquinta Edición. Ed. Comares. 2014.

25 STJUE de 28 de marzo de 2000, asunto C-7/98, Krombach, ECLI:EU:C:2000:164

${ }^{26}$ M. Gómez Jene, “Arbitraje Comercial Internacional”. Ed. Civitas. 2018.

${ }^{27}$ En este sentido, en sede de anulación del laudo, el Tribunal Constitucional ha recordado en su STC 17/2021, de 15 de febrero de 2021, Larios (ECLI:ES:TC:2021:17) que el Tribunal no puede entrar a valorar el contenido del laudo. El amparo trae causa de una sentencia dictada por el TSJ de Madrid, al que se le solicitaba la nulidad de un laudo de disolución de sociedad 
32. De todo lo hasta aquí dicho que puede llegar a varias conclusiones. La primera es que el derecho de defensa está reconocido y protegido por el CEDH. La segunda que, puesto que los principios generales europeos se inspiran en instrumentos internacionales en los que participan los Estados, como fue el caso del CEDH, el derecho de defensa se encuentra dentro de ellos, por lo que su observancia debe darse en todo proceso y en todos los países. Y, finalmente, que el TJUE garantiza que se respeten tales principios. Por ende, el derecho de defensa debe protegerse y garantizarse en todos los procesos y su inobservancia podría dar lugar a una vulneración del orden público internacional.

33. Con anterioridad se ha puesto de manifiesto la importancia que tiene la STJUE Krombach en relación con el derecho de defensa y su interpretación, así como que el presente apartado se iba a inspirar en lo establecido en ella. Así pues, es necesario hacer un alto cuando el TJUE cita al Tribunal Europeo de Derechos Humanos (TEDH en adelante), ya que éste dice que "ha declarado repetidamente en materia penal que, aunque no sea absoluto, el derecho de todo acusado a ser efectivamente defendido por un abogado, en su caso nombrado de oficio, figura entre los elementos fundamentales del proceso justo y que un acusado no pierde tal derecho por el mero hecho de no estar presente en los debates".

34. Es necesario resaltar las palabras del TEDH en este aspecto, pues al hablar del derecho de defensa indica que " $n o$ [es] absoluto". No debe malinterpretarse y pensar que puede no aparecer el derecho de defensa en un proceso y no haber vulneración del orden público internacional. En absoluto es así, pues el derecho a la defensa siempre existe, a lo que el tribunal se refiere es que pueden haber ocasiones en las que esté justificado no dar audiencia al demandado, sin que ello comporte ningún tipo de atentado contra los derechos de defensa inherentes al proceso. Efectivamente, hay ocasiones en las que puede ser incluso el propio tribunal el que impida al demandado, por cualquier motivo, comparecer en juicio y ello no será una vulneración del orden público internacional.

35. Esto encuentra su plasmación en la STJUE Trade Agency donde el tribunal expone que “(...), el Tribunal de Justicia ya ha declarado sobre este particular que los derechos fundamentales no constituyen prerrogativas absolutas, sino que pueden implicar restricciones, siempre que respondan efectivamente a objetivos de interés general perseguidos por las medidas de que se trate y no constituyan, habida cuenta del objetivo que se pretende alcanzar, un menoscabo manifiesto y desproporcionado a los derechos así garantizados" ${ }^{28}$. En idéntico sentido la STJUE Gambazzi, pues explica que "Es cierto que no cabe concebir los derechos fundamentales, como es el caso del respeto del derecho de defensa, como prerrogativas absolutas, sino que pueden implicar restricciones. No obstante, estas últimas deben responder efectivamente a objetivos de interés general perseguidos por la medida de que se trate y no constituir, habida cuenta del objetivo que se pretende alcanzar, un menoscabo manifiesto y desproporcionado a los derechos así garantizados." 29

36. Así pues, el derecho de defensa es un principio general reconocido en múltiples instrumentos tanto nacionales como internacionales, como por ejemplo en el CEDH. No obstante, existen supuestos en los que puede limitarse, en el sentido de no ser necesario dar audiencia a la parte. Pueden haber situaciones en las que una de las partes no comparezca y aun así no ver vulnerado su derecho de defensa, sin que ello derivase una enervación del orden público internacional. No obstante, los casos en que se pueda privar a una de las partes de su derecho de defensa tienen que responder a fines muy específicos y

por considerarlo una de las partes contrario al orden público. En su sentencia el TJUE consideraba que el laudo dictado “(...) no da respuesta a todas las cuestiones planteadas en el arbitraje, no valora las pruebas en su integridad y no contiene una motivación suficiente para llegar a una conclusión tan importante como la disolución de la sociedad". Sin embargo, el TC expone en esta sentencia que "la valoración del órgano judicial competente sobre una posible contradicción del laudo con el orden público, no puede consistir en un nuevo análisis del asunto sometido a arbitraje, sustituyendo el papel del árbitro en la solución de la controversia, sino que debe ceñirse al enjuiciamiento respecto de la legalidad del convenio arbitral, la arbitrabilidad de la materia y la regularidad procedimental del desarrollo del arbitraje".

28 STJUE de 6 de septiembre de 2012, Trade Agency, asunto C619/10. ECLI:EU:C:2012:531

29 STJUE de 2 de abril de 2009, Gambazzi, asunto C394/07. ECLI:EU:C:2009:219 
estar muy bien justificados, para que no constituyan un menoscabo de los derechos garantizados y evitar que el tribunal haga uso de esta posibilidad de manera arbitraria.

\section{B) EI derecho de defensa en Derecho español}

37. El derecho de defensa se encuentra reconocido en la Constitución Española ${ }^{30}$, en particular el art. $24^{31}$ plasma el derecho que tienen los ciudadanos a defenderse en juicio. Esto se traduce en que este derecho también cuenta con gran relevancia en el ordenamiento jurídico español, en tanto en cuanto se encuentra protegido por la Norma Fundamental del Estado. Aunque todos los organismos públicos están sujetos a la CE, así como los particulares, es el Tribunal Constitucional (TC en adelante) el encargado de interpretar y asegurarse que se cumple lo contenido en la CE, cuando así se le pida a través del recurso de amparo.

38. Al igual que se ha hecho en el epígrafe anterior, donde se ha seguido la interpretación del concepto "derecho de defensa" dada por el TJUE por ser éste el encargado de establecer los límites del orden público y su intervención, en el caso español se van a seguir las pautas dadas por el Alto Tribunal en diversas sentencias para explicar la interpretación que recibe este derecho dentro de nuestro sistema. Para ello hay que comenzar con la mención de la sentencia del TC 132/199132, donde el tribunal establece en relación con el procedimiento de exequátur de sentencia extranjera que “(...), aunque los derechos fundamentales y libertades públicas que la Constitución garantiza sólo alcanzan plena eficacia alli donde rige el ejercicio de la soberanía española, nuestras autoridades públicas, incluidos los Jueces y Tribunales, no pueden reconocer ni recibir resoluciones dictadas por autoridades extranjeras que supongan vulneración de los derechos fundamentales y libertades públicas garantizadas constitucionalmente (...). El orden público del foro ha adquirido, así, un contenido peculiar impregnado por las exigencias de la Constitución y, en particular, (...), por las exigencias que impone el art. 24 CE”.

39. De esta manera el TC asienta la base sobre la que se construye el concepto de orden público dentro del territorio español. Éste se activará, entre otros, en los procesos de reconocimiento de resoluciones extranjeras cuando éstas sean contrarias al contenido de la $\mathrm{CE}$, ya que en ella se incluyen los derechos fundamentales y libertades públicas de la sociedad española. Pero continúa el tribunal y dice que "Estas exigencias suponen que el Tribunal español, a la hora de decidir sobre la ejecución en España de una resolución judicial extranjera, ha de tener en cuenta las garantías contenidas en el art. 24 CE y ha de comprobar si, al dictarse la resolución cuya ejecución se solicita, se han respetado las citadas garantias".

40. Si se va de atrás para adelante se pueden extraer las siguientes ideas. En primer lugar, el juez requerido para otorgar el exequátur no puede entrar a decidir sobre el fondo de la cuestión o si la resolución ha sido más o menos acertada, únicamente puede comprobar que se han respetado los principios generales y normas imperativas que constituyen la base del sistema jurídico español. Esta necesidad de ajustarse a Derecho incluye tanto las normas procesales, los requisitos de forma que deben observarse en el proceso y en la resolución, como las normas materiales de carácter imperativo o esencial y su no vulneración. En segundo lugar, esas consideraciones procesales van a suponer el límite básico y esencial

\footnotetext{
${ }^{30}$ Constitución Española (BOE núm. 311, de 29 de diciembre de1978. Ref. BOE-A-1978-31229).

31 Art. 24 CE: "1. Todas las personas tienen derecho a obtener la tutela efectiva de los jueces y tribunales en el ejercicio de sus derechos e intereses legítimos, sin que, en ningún caso, pueda producirse indefensión. 2. Asimismo, todos tienen derecho al Juez ordinario predeterminado por la ley, a la defensa y a la asistencia de letrado, a ser informados de la acusación formulada contra ellos, a un proceso público sin dilaciones indebidas y con todas las garantías, a utilizar los medios de prueba pertinentes para su defensa, a no declarar contra sí mismos, a no confesarse culpables y a la presunción de inocencia. La ley regulará los casos en que, por razón de parentesco o de secreto profesional, no se estará obligado a declarar sobre hechos presuntamente delictivos."

32 STC 132/1991, de 17 de junio de 1991. BOE núm. 162, de 8 de julio de 1991. ECLI:ES:TC:1991:132
} 
que debe respetarse y que constituyen el contenido del orden público internacional. Y ese contenido, tercera idea, está plasmado en la CE.

41. Si se prosigue la línea de interpretación del art. $24 \mathrm{CE}$ que hace el TC, se encuentra que " $L a$ indefensión consiste en un impedimento del derecho a alegar y de demostrar en el proceso los propios derechos y, en su manifestación más trascendente, es la situación en la que se impide a una parte, por el órgano judicial, en el curso del proceso, el ejercicio del derecho de defensa, privándola de ejercitar su potestad de alegar y, en su caso, justificar sus derechos e intereses para que le sean reconocidos, o para replicar dialécticamente las posiciones contrarias en el ejercicio del indispensable principio de contradicción." 33

42. Pero añade además que la indefensión "no nace, (...), de la sola y simple infracción por los órganos judiciales de las reglas procesales, pues el quebrantamiento de esta legalidad no provoca, en todos los casos, la eliminación o disminución sustancial de los derechos que corresponden a las partes en razón de su posición propia en el procedimiento ni, en consecuencia, la indefensión que la Constitución proscribe. ${ }^{\prime 34}$ Por tanto, la privación de alguno de los derechos contenidos en el art. 24 CE no constituye directamente una infracción constitucional ni una vulneración del orden público internacional. Es más, no se producirá indefensión del interesado cuando éste haya actuado con impericia o negligencia y no haya hecho uso de sus posibilidades de defensa, ignorando los remedios hábiles de que dispone para hacer valer sus intereses y cooperando al menoscabo de su posición procesal, incluso aunque exista quebrantamiento de la legalidad procesal por parte del juzgador ${ }^{35}$.

43. De todo lo hasta aquí dicho se puede extraer que efectivamente el derecho de defensa está garantizado en la CE y se intenta garantizar en todos los procesos jurisdiccionales. Sin embargo, no todo quebrantamiento procesal deriva en una infracción constitucional y vulneración del orden público internacional, sino que hay veces en las que éste no constituye una transgresión de la Constitución y, por ende, del orden público internacional.

44. De vuelta nuevamente al supuesto tratado en el presente comentario hay que decir que la ausencia del demandado no ha constituido una vulneración de su derecho de defensa. Tal y como se ha expresado en el epígrafe anterior, la incomparecencia del demandado parece que fue voluntaria, pues no hace mención el auto a ningún intento fallido de notificación del procedimiento. Es por ello que no constituye una enervación o limitación del derecho que tiene toda persona a defenderse en juicio. Cosa distinta habría sido que el propio tribunal hubiese decidido no escuchar lo que tuviese que decir la demandada o que hubiera limitado su actuación en el proceso, en cuyo caso debería haber una motivación que justificase su decisión.

\section{Conclusiones}

45. Se debe partir de la correcta actuación del tribunal a la hora de continuar el procedimiento incluso con la incomparecencia de la parte demandada. Sin embargo, la situación habría sido distinta si esa ausencia se hubiese producido por causas distintas a la voluntad del demandado o hubiese ocurrido en un paso anterior, concretamente en el procedimiento arbitral. $Y$ es que la presencia o ausencia del demandado en un procedimiento puede tener distintas consecuencias jurídicas. El cuándo surge esa ausencia también tiene una gran relevancia, pues no es lo mismo que se dé en un procedimiento ordinario que en uno de exequátur, ya que las consecuencias que se van a derivar de uno u otro serán diferentes. Gracias al supuesto tratado en el auto del TSJ de Madrid, se ha podido abordar la relación que tiene el

33 STC 89/1986, de 1 de julio de 1986. BOE núm. 174, de 22 de julio de 1986. ECLI:ES:TC:1986:89

34 STC 102/1987, de 17 de junio de 1987. BOE núm. 163, de 9 de julio de 1987. ECLI: ES:TC:1987:102

${ }_{35}$ STC 109/1985, de 8 de octubre de 1985. BOE núm. 265, de 5 de noviembre de 1985. ECLI:ES:TC:1985:109 
derecho de defensa con las distintas instancias, los resultados a los que se puede llegar y en qué momentos debe aparecer el orden público para preservarlo frente a injerencias por parte de los tribunales. Por ello, del supuesto estudiado se pueden extraer varias reflexiones.

Primera. El orden público internacional es el límite con el que cuentan los tribunales para denegar una resolución o laudo arbitral extranjero. El problema surge cuando se intenta decidir qué es lo que se comprende dentro de él, pues al ser un concepto jurídico indeterminado no hay una lista tasada de supuestos cuya comisión conlleve a una violación del orden público internacional. Además, a pesar de tener el término "internacional", es un concepto de formulación nacional, por lo que son los propios Estados los que decidan qué va a estar incluido en ese concepto, qué es fundamental y básico en su país y cuándo una enervación de esos principios va a causar la aparición de la excepción de orden público para poder denegar el exequátur.

Segunda. En el Derecho actual de todos los Estados civilizados el derecho de defensa es un derecho esencial, inherente a todo proceso y que debe garantizarse. Su inobservancia podría ser motivo suficiente para activar la excepción de orden público internacional en su vertiente procesal, lo que deriva en no reconocer una resolución o laudo arbitral extranjero. Pero esto no es así del todo, pues hay circunstancias en las que los tribunales pueden limitar este derecho y ello no produciría un quebrantamiento de los derechos fundamentales. Esto es así para evitar actuaciones dolosas por parte del demandado, por lo que hay que estudiar muy bien el caso que se presenta para decidir si se puede aplicar o no el orden público internacional en su vertiente procesal como motivo para denegar el reconocimiento, porque éste no deja de ser una excepción y no una prerrogativa de los tribunales para denegar la transposición de toda aquella resolución que intente entrar en el país y que no sea de su agrado.

Tercera. El propio TJUE ha apreciado en diversas ocasiones momentos en los que se ha modulado a una parte su derecho de defensa por parte de un tribunal, sin constituir ésta una privación total sino más bien una limitación. Podrá la parte seguir ejercitando otros medios de defensa, pero no la comparecencia en juicio y ello no supone ningún perjuicio de su derecho. La misma línea de pensamiento es compartida por el TC español al decir que no toda infracción procesal va a ser determinante de una indefensión, sino que para que se produjese tendría que haber una privación total de cualquier medio de defensa posible. Ambos tribunales son coherentes, pues el derecho de defensa es un derecho fundamental, sí, pero eso no se convierte en un escudo tras el cual el demandado pueda esconderse y entorpecer el curso normal del proceso.

Cuarta. Si la ausencia del demandado se produce por una actuación malintencionada de éste, donde persiga obstaculizar el desarrollo del proceso y menoscabar los derechos de la contraparte, por supuesto que no merece protección por parte del orden público internacional. Porque de proporcionársele, se estaría abriendo una puerta a la oportunidad de esquivar el procedimiento original al que se debía haber sometido, y en el caso del arbitraje incluso que decidió, y después alegar que se produjo una violación de su derecho fundamental de defensa para intentar que no se reconozca esa resolución.

Quinta. Cuestión distinta es si esa ausencia se produjo por cualquier causa que no sea imputable a él, ya sea una mala notificación o no haberla realizado con tiempo suficiente. Ahora bien, si bien es cierto que estos supuestos sí supondrían una violación del derecho de defensa, también lo es que si el demandado tuvo conocimiento del proceso existente en su contra en cualquier momento, debería haber aparecido y ejercitado las acciones que todavía le quedasen y no quedarse impasible viendo el trascurrir del tiempo para después alegar la vulneración. De hacer esto segundo, el orden público internacional en su aspecto procesal no sería aplicable, pues volvería a existir una mala actuación por parte del demandado. En este caso se consideraría que existió una situación de rebeldía, con las consecuencias legales que de ello derivan. Para que la ausencia produzca un menoscabo del derecho de defensa, ésta debe ser por causas imputables únicamente al tribunal. 